\title{
Influence of Environment on Ageing Behaviour of the Polyurethane Film
}

\author{
Yanzhi WANG ${ }^{1 *}$, Zonghui SUN ${ }^{1}$, Jifeng TIAN ${ }^{2}$, Haiyan WANG ${ }^{1}$, Huicong WANG ${ }^{1}$, \\ Yingliang JI ${ }^{1}$ \\ ${ }^{1}$ Hebei Key Laboratory of Applied Chemistry, College of Environmental and Chemical Engineering, Yanshan University,
Qinhuangdao 066004, P.R. China
${ }^{2}$ College of Civil Engineering \& Mechanics, Yanshan University, Qinhuangdao 066004, P.R. China
cross ${ }^{\text {ref }}$ http://dx.doi.org/10.5755/j01.ms.22.2.12935
}

Received 20 August 2015; accepted 19 December 2015

\begin{abstract}
In this work, UV-Vis spectra, FT-IR spectra, colour difference, yellowness index, and SEM micrographs were used to study the accelerated ageing behaviour of polyurethane films that exposed to UV radiation, $\mathrm{O}_{3}$ atmosphere, and $\mathrm{UV} / \mathrm{O}_{3}$ integrated environment. During 200 hours of exposure in three different environment, the UV absorbance, the colour difference, the yellowness, and the absorption of $-\mathrm{NH} /-\mathrm{OH}$ and $-\mathrm{C}=\mathrm{O}$ bands in FT-IR spectra of the films increase gradually with increasing exposure time, respectively, and the films exposed to the three environments have different colour difference, yellowness index, UV-Vis spectra, and FT-IR spectra. The films are vulnerable to degradation and yellowing in the following environment order: $\mathrm{O}_{3}<\mathrm{UV}<\mathrm{UV} / \mathrm{O}_{3}$. After exposure to $\mathrm{UV}$ radiation or $\mathrm{O}_{3}$ atmosphere, some degradation products and blisters are formed on the film surface. After exposure to $\mathrm{UV} / \mathrm{O}_{3}$ integrated environment, there are strip blisters and micro-cracks on the film surface, and exists an obvious synergism between UV radiation and $\mathrm{O}_{3}$ atmosphere in accelerating the ageing of the polyurethane films.

Keywords: polyurethane films, ageing, synergism.
\end{abstract}

\section{INTRODUCTION}

Thermoplastic polyurethane are AB-type copolymers of alternating soft and hard segments [1]. Recently, the thermoplastic polyurethane is becoming one of the outstanding candidate materials for aircraft weathering layer or high-altitude balloon, because it has excellent performances, such as chemical resistance, high-flexibility and good adhesion with other materials. However, one of the particular disadvantages of the polyurethane materials is their extreme sensitivity to some environments such as UV radiation, temperature, humidity and so on. This is a major limitation which relates to their use as surface coatings in outdoor applications. Many papers [2-8] have been published on the degradation of polyurethane material, including oxidation initiated by heat and light, hydrolysis, thermolysis, and degradation at high temperatures, etc. In addition, atmospheric ozone usually causes the degradation of polymers. Ozone concentrations of less than $1 \mathrm{ppb}$ can severely attack non-resistant elastomers if they are in the strained condition. Therefore, ozone attack is often the most important effect on properties of polymer exposed to space environment. Nowadays the ozone resistance of polymer products is of paramount importance, because the problem has worsened as atmospheric ozone concentrations have gradually increased [9].

If the polyurethane materials are applied to the aircraft weathering layer or the high-altitude balloon, the polyurethane film will be exposed to harsh environments including UV radiation and $\mathrm{O}_{3}$ atmosphere. The internal molecular structure of the polyurethane film may change continuously, resulting in the changes of the chemical and physical properties of the materials. However, commercial

\footnotetext{
${ }^{*}$ Corresponding author. Tel.: 0335-8061569; fax: 0335-8061569.

E-mail address: hhwyz@ysu.edu.cn (Y. Wang)
}

the polyurethane material are chemically complex, and contain thermally and hydrolytically labile groups such as urea, isocyanurate, ester, and ether moieties, as well as various additives. Therefore, it is not simple to assess their present state of stability and remaining service life. Accelerated ageing tests can be used to assess ageing behaviour of the polyurethane films over a short time. The research could provide effective data support for the application of the polyurethane material in aircraft weathering layer or high-altitude balloon, and help to design new ones. This is a challenge to those who care for such items.

Our research group studied effects of additives on weather-resistance properties of polyurethane films exposed to ultraviolet radiation and ozone atmosphere [10]. Until now, we have not found other literature compared the accelerated ageing behaviour of the polyurethane film exposed to $\mathrm{UV}$ radiation, $\mathrm{O}_{3}$ atmosphere and $\mathrm{UV} / \mathrm{O}_{3}$ environment. In this study, the accelerated ageing behaviour of polyurethane films exposed to UV radiation, $\mathrm{O}_{3}$ atmosphere, and $\mathrm{UV} \mathrm{O}_{3}$ integrated environment was investigated, respectively, and whether there was synergism between $\mathrm{UV}$ radiation and $\mathrm{O}_{3}$ atmosphere in accelerating the ageing of polyurethane films was also analysed.

\section{EXPERIMENTAL DETAILS}

\subsection{Materials}

Polyether polyurethane (PU) pellet was purchased from BASF SE Co. (Germany), N,N-dimethylformamide (DMF) (AR.) was purchased from Tianjin Kay Tong Chemical Reagent Co., Ltd.(Tianjin, China). Butanone (AR.) was purchased from Tianjin Sailboats Chemical Reagent Technology Co., Ltd. (Tianjin, China). 


\subsection{Specimen preparation}

The mixed solvent was obtained by mixing DMF and butanone in the mass ratio of 7:2. Polyurethane pellets of $50 \mathrm{~g}$ were gradually added to the mixed solvent of $50 \mathrm{~g}$ according to the mixed solvent and the pellets with the mass ratio of 1 to 1 , and the above mixture was slowly heated to about $60{ }^{\circ} \mathrm{C}$, and the mixture was vigorously stirred for $2 \mathrm{~h}$, and then the slurry with $12-13$ wt.\% solids content was obtained. In this experiment, the films for exposure experiments were prepared by using a spin coater at the rate of $2000 \mathrm{r} / \mathrm{min}$ for $5 \mathrm{~s}$, dried in a vacuum oven at $50{ }^{\circ} \mathrm{C}$ for $12 \mathrm{~h}$. Calcium fluoride discs with a thickness of $2 \mathrm{~mm}$ and a diameter of $25 \mathrm{~mm}$ were selected as the substrate of PU films because $\mathrm{CaF}_{2}$ discs have excellent moisture, heat resistance properties, and it is transparent to both UV-visible and infrared radiation. Because the films substrate for testing SEM micrographs should be conductive, and $\mathrm{CaF}_{2}$ disc is not conductive, the films for testing SEM micrographs were coated on the hard aluminum foil by using a coating machine at the rate of $6 \mathrm{~cm} / \mathrm{s}$. The films thickness is approximately 100 microns. The films were dried in a vacuum oven at $50{ }^{\circ} \mathrm{C}$ for $12 \mathrm{~h}$. The obtained PU films with thickness of $12-13 \mu \mathrm{m}$ were placed in a desiccator.

\subsection{Ageing tests}

The ageing tests of PU films were carried out in a selfdesigned ageing device. UVB-313 fluorescent UV lamp (U.S. Q-Lab Corporation, $290 \mathrm{~nm}<\lambda<400 \mathrm{~nm}$ ) was used as a light source, and AD-XF-5 P ozone machine (Jinan Jie Anritsu Technology Co., Ltd.) was used as an ozone source in the ageing device. UV irradiation intensity was $400 \pm 20 \mu \mathrm{W} / \mathrm{cm}^{2}$, and the ozone concentration was $100 \pm 2 \mathrm{ppm}$. UV ageing, $\mathrm{O}_{3}$ ageing and $\mathrm{UV} / \mathrm{O}_{3}$ integrated ageing were performed with the films at ambient relative humidity, respectively. The ageing time of the films was 20 h, 60 h, 120 h, 160 h, and 200 h.

\subsection{Properties characterization}

UV-Vis spectra of all the films were collected on UV2550 UV-Vis spectrophotometer (Shimadzu Corporation, Japan) in the wavelength range of $190-800 \mathrm{~nm}$ at $0.5 \mathrm{~nm}$ increments. All FT-IR spectra in transmission mode were collected on a Nicolet iS10 infrared spectrometer (Thermo Fisher Scientific) in the wave number range of $400-4000 \mathrm{~cm}^{-1}$. Spectral resolution of $4 \mathrm{~cm}^{-1}$ was used. The colour difference and the yellowness index of all the films after exposure were recorded using a CR-10 colorimeter (Konica Minolta Corporation, Japan). The Scanning Electron Microscopy (SEM) studies were performed using S-4800 field-emission scanning electron microscope (Hitachi Limited), and the operating voltage was $15 \mathrm{kV}$. The sample surface was sprayed with gold prior to imaging.

\section{RESULTS AND DISCUSSION}

\subsection{UV-Vis spectra}

$\mathrm{UV}-\mathrm{Vis}$ spectra of PU films exposed to UV radiation, $\mathrm{O}_{3}$ atmosphere and $\mathrm{UV} / \mathrm{O}_{3}$ integrated environment at the different exposure time are shown in Fig. 1.

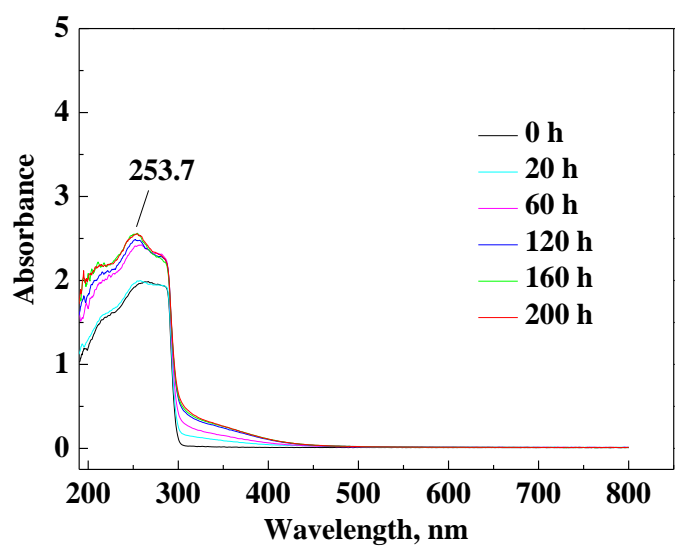

a
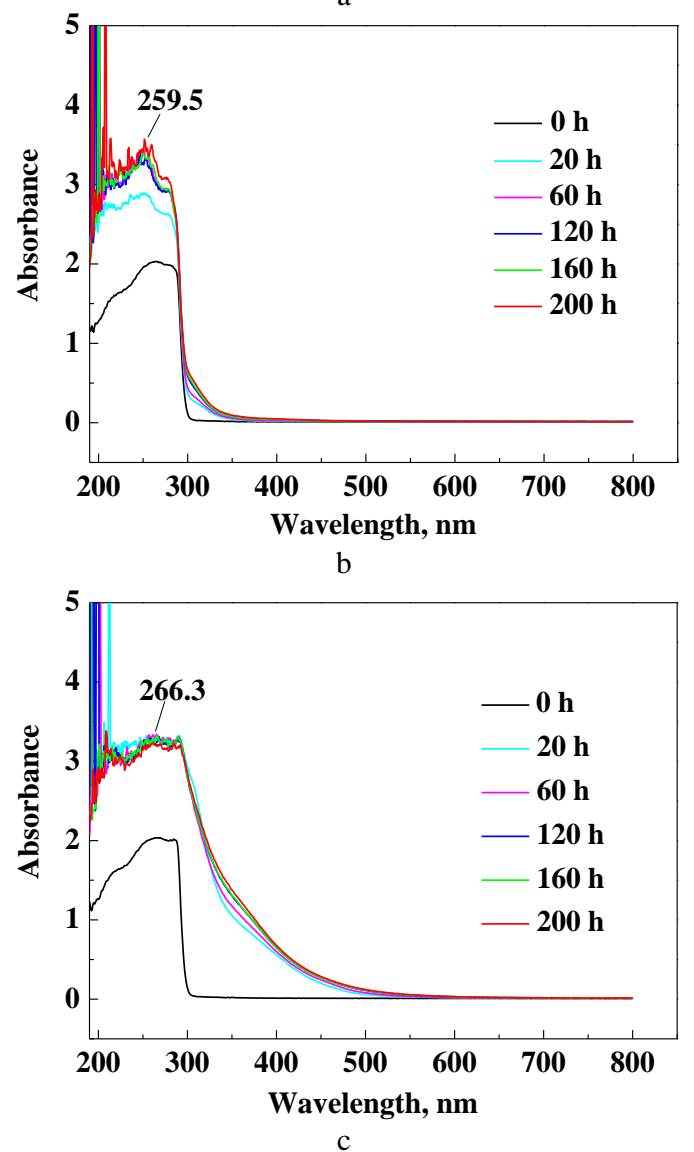

Fig. 1. a-UV-Vis spectra of PU films exposed to UV radiation; $\mathrm{b}-\mathrm{UV}-\mathrm{Vis}$ spectra of PU film exposed to $\mathrm{O}_{3}$ atmosphere $\mathrm{O}_{3}$ atmosphere; $\mathrm{c}-\mathrm{UV}-\mathrm{V}$ is spectra of $\mathrm{PU}$ film exposed to $\mathrm{UV} / \mathrm{O}_{3}$ integrated environment

As can be seen, UV-Vis absorbance gradually increases with prolonged exposure time, indicating that the ageing degree of PU films gradually deepens. Secondly, the absorption peaks near $200 \mathrm{~nm}$, which are ascribed to the $n-\pi^{*}$ transition from carbonyl groups, gradually increase and widen with prolonged exposure time. It suggests that the amount of carbonyl compounds is continuously increasing, and the type of carbonyl compounds is constantly transforming during the exposure in $\mathrm{O}_{3}$ atmosphere and $\mathrm{UV} / \mathrm{O}_{3}$ integrated environment [8]. Thirdly, a bathochromic shift is observed in the range of wavelength greater than $300 \mathrm{~nm}$ in Fig. 1. This indicates that PU molecule may be partially transformed into a quinine-imide chromophore during the degradation process [8]. The films exposed to various environments have 
different bathochromic shift in UV-Vis spectra. The environment order of the bathochromic shift is as follows, $\mathrm{O}_{3}<\mathrm{UV}<\mathrm{UV} / \mathrm{O}_{3}$. This suggests that the films are vulnerable to degradation and yellowing in the above environment order.

\subsection{FT-IR spectra}

Fig. 2 shows FT-IR spectra of PU films exposed to UV radiation, $\mathrm{O}_{3}$ atmosphere and $\mathrm{UV}_{3} \mathrm{O}_{3}$ integrated environment at different exposure time. As it can be seen, the absorption peaks between $3700-3000 \mathrm{~cm}^{-1}$ characterizes $\mathrm{N}-\mathrm{H}$ and $\mathrm{O}-\mathrm{H}$ stretch vibrations. The peak at ca. $1720 \mathrm{~cm}^{-1}$ can be assigned to $\mathrm{C}=\mathrm{O}$ stretching vibration in ester structure, $1531 \mathrm{~cm}^{-1} \mathrm{~N}-\mathrm{H}$ deformation (amide II band), $1416 \mathrm{~cm}^{-1} \quad \mathrm{C}-\mathrm{N}$ stretching. The region of $1300-1100 \mathrm{~cm}^{-1}$ is characteristic of $\mathrm{C}-\mathrm{O}$ stretching vibration in urethane structure. The absorption peak at ca. $1597 \mathrm{~cm}^{-1}$ could be attributed to $\mathrm{C}=\mathrm{C}$ skeletal vibration in aromatic ring. While the vibrational modes between $3000 \mathrm{~cm}^{-1}$ and $2800 \mathrm{~cm}^{-1}$ can provide strong indication of $\mathrm{C}-\mathrm{H}$ stretching. The changes in FT-IR spectra exhibit a number of interesting and novel groups associated with polyurethane [8]. The changes of the main functional groups are summarized in Table 1.

Table 1. FT-IR absorption band changes of the films exposed to $\mathrm{UV}$ radiation, $\mathrm{O}_{3}$ atmosphere, and $\mathrm{UV} / \mathrm{O}_{3}$ integrated environment

\begin{tabular}{|c|c|c|}
\hline \multicolumn{2}{|c|}{ Wavenumber, $\mathrm{cm}^{-1}$} & \multirow{2}{*}{ Absorption band } \\
\hline Increase & Decrease & \\
\hline \multirow[t]{3}{*}{$3500-3200$} & & $-\mathrm{NH} /-\mathrm{OH}$ stretching vibration \\
\hline & 2940 & $\begin{array}{l}\text { asymmetrical stretching } \\
\text { vibrations of the } \mathrm{CH}_{2} \text { group }\end{array}$ \\
\hline & 2850 & $\begin{array}{l}\text { symmetrical stretching } \\
\text { vibrations of the } \mathrm{CH}_{2} \text { group }\end{array}$ \\
\hline \multirow[t]{4}{*}{$1763-1640$} & & $-\mathrm{C}=\mathrm{O}$ stretching of the urethane \\
\hline & 1600 & $\begin{array}{l}\text { the stretching vibration of the } \\
\text { double bonds in the aromatic } \\
\text { ring }\end{array}$ \\
\hline & 1530 & $\begin{array}{l}\text { the coupling peak of }-\mathrm{NH} \\
\text { bending and }-\mathrm{CN} \text { stretching } \\
\text { motion }\end{array}$ \\
\hline & 1230 & $-\mathrm{C}-\mathrm{C}$ stretching peak \\
\hline $3500-3200$ & 1110 & $-\mathrm{C}-\mathrm{O}$ absorption peak \\
\hline
\end{tabular}

As it can be seen, the absorption in the region of $3500-3200 \mathrm{~cm}^{-1}$ significantly increases. This suggests the formation of hydroxyl groups in PU films. The absorption in the region of $2390-2270 \mathrm{~cm}^{-1}$ is a noticeable phenomenon in Fig. $2 \mathrm{c}$, which may be attributed to the formation of $-\mathrm{NCO}$ during $\mathrm{UV} / \mathrm{O}_{3}$ ageing process [10]. The increase of the absorption in the region of $1763-$ $1640 \mathrm{~cm}^{-1}$ indicates that new carbonyl species including quinine-imide structure may generate [11]. The peaks at $1530 \mathrm{~cm}^{-1}, 1230 \mathrm{~cm}^{-1}$ and $1110 \mathrm{~cm}^{-1}$ gradually decrease as a function of exposure time. These suggest that the bonds of $-\mathrm{C}-\mathrm{O}$ and $-\mathrm{CN}$ break, and the bonds of $-\mathrm{C}=\mathrm{O},-\mathrm{NH}$ and -OH appear in the molecules of PU films during exposure [12]. A loss of the peak intensity at $1600 \mathrm{~cm}^{-1}$ could be attributed to the conversion of benzene ring to quinine or azo structure, which may be the reason for yellowing of the films $[14,15]$. At the same time, there is different degree of the variation for the above-mentioned peaks in different environments. The order of the variation degree in various environment is as follows, $\mathrm{O}_{3}<\mathrm{UV}<\mathrm{UV} / \mathrm{O}_{3}$. This suggests that the films are vulnerable to degradation and yellowing in the above order. These are basically consistent with the results of the UV-Vis spectra.

\subsection{Colour change and synergistic ageing effect}

The colour difference of $\mathrm{PU}$ films exposed to $\mathrm{UV}$ radiation, $\mathrm{O}_{3}$ atmosphere, and $\mathrm{UV} / \mathrm{O}_{3}$ integrated environment are shown in Table 2. "UV $+\mathrm{O}_{3}$ " represents algebraic sum of the colour difference of the film exposed to $\mathrm{UV}$ radiation and that to $\mathrm{O}_{3}$ atmosphere at the same time. It can be seen that the colour difference of $\mathrm{PU}$ films exposed to $\mathrm{UV}$ radiation, $\mathrm{O}_{3}$ atmosphere, and $\mathrm{UV} / \mathrm{O}_{3}$ integrated environment increase with increasing exposure time, respectively.
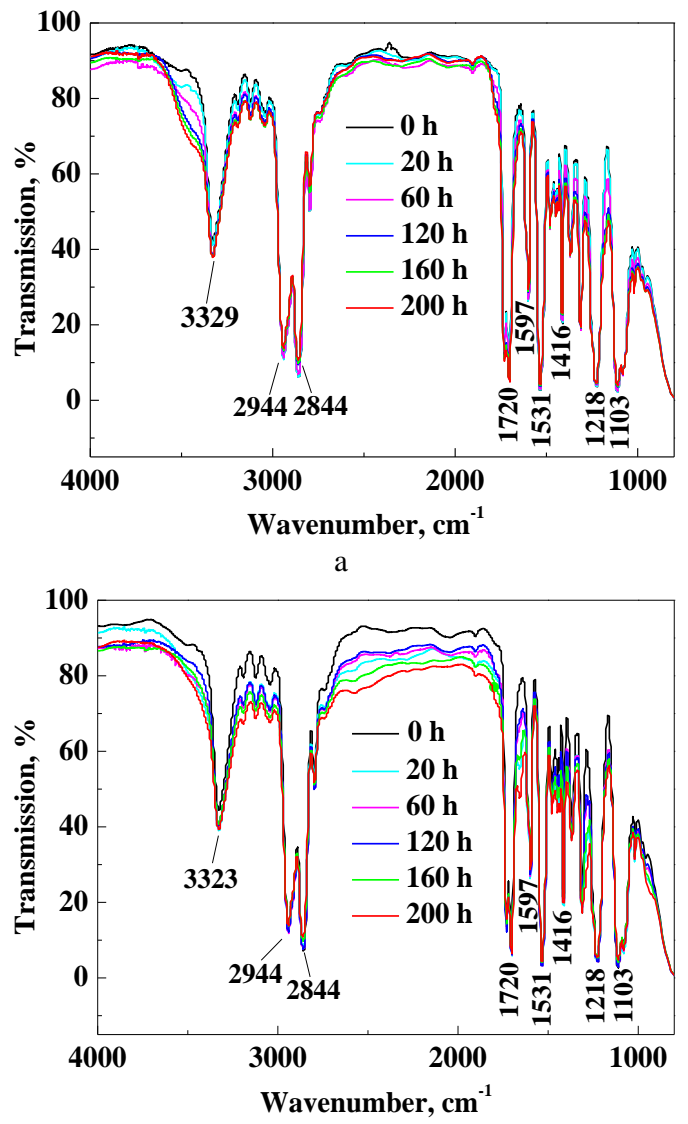

b

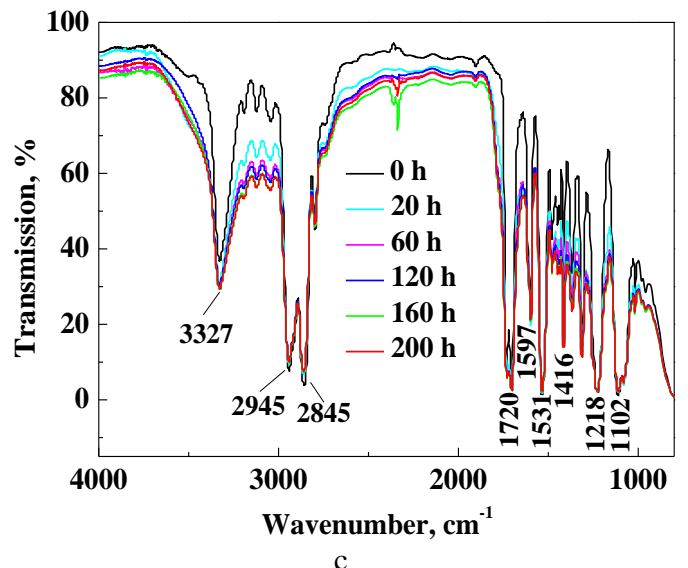

Fig. 2. a-FT-IR spectra of PU films exposed to UV radiation; b-FT-IR spectra of PU films exposed to $\mathrm{O}_{3}$ atmosphere; c-FT-IR spectra of $\mathrm{PU}$ films exposed to $\mathrm{UV} / \mathrm{O}_{3}$ integrated environment 
Secondly, the films exposed to various environments have different colour difference. The colour difference order is as follows, $\mathrm{O}_{3}<\mathrm{UV}<\mathrm{UV} / \mathrm{O}_{3}$, which suggests that the films are vulnerable to degradation and yellowing in the above environment order. Thirdly, the colour difference of the film exposed to $\mathrm{UV} / \mathrm{O}_{3}$ integrated environment is significantly greater than the value of "UV $+\mathrm{O}_{3}$ " at the same time. This suggests that an obvious synergistic ageing effect between $\mathrm{UV}$ ageing and $\mathrm{O}_{3}$ ageing exists when the colour difference is used as the evaluation index. This may be explained by the phenomenon that atomic oxygen generated from ozone accelerates the loss of the activity of the polymer chain in the ultraviolet irradiation.

Table 2. The colour difference of PU film exposed to various environments

\begin{tabular}{|c|c|c|c|c|c|c|}
\hline \multirow{2}{*}{ Environment } & \multicolumn{7}{|c|}{ Time, $\mathrm{h}$} \\
\cline { 2 - 7 } & 0 & 20 & 60 & 120 & 160 & 200 \\
\hline $\mathrm{UV}$ & 0 & 4.35 & 4.00 & 5.60 & 6.15 & 6.15 \\
\hline $\mathrm{O}_{3}$ & 0 & 0.60 & 1.70 & 2.65 & 2.90 & 3.40 \\
\hline $\mathrm{O}_{3} / \mathrm{UV}$ & 0 & 34.00 & 38.30 & 40.05 & 39.65 & 40.85 \\
\hline $\mathrm{O}_{3}+\mathrm{UV}$ & 0 & 4.95 & 5.70 & 8.25 & 9.05 & 9.55 \\
\hline
\end{tabular}

Table 3 demonstrates the yellowness index of PU films exposed to $\mathrm{UV}$ radiation, $\mathrm{O}_{3}$ atmosphere, and $\mathrm{UV} / \mathrm{O}_{3}$ integrated environment, in which " $\mathrm{UV}+\mathrm{O}_{3}$ " represents algebraic sum of the yellowness index of the film exposed to $\mathrm{UV}$ radiation and that to $\mathrm{O}_{3}$ atmosphere at the same time. The changed rule of the yellowness index is consistent with that of the colour difference of the films exposed to $\mathrm{UV}$ radiation, $\mathrm{O}_{3}$ atmosphere, and $\mathrm{UV} / \mathrm{O}_{3}$ integrated environment. Secondly, the films exposed to various environments have different yellowness index. The order of the yellowness index is as follows, $\mathrm{O}_{3}<\mathrm{UV}<\mathrm{UV} / \mathrm{O}_{3}$. This suggests that the films are vulnerable to degradation and yellowing in the above environment order. Thirdly, an obvious synergistic ageing effect between UV ageing and $\mathrm{O}_{3}$ ageing exists when the yellowness index is used as the evaluation index.

Table 3. The yellowness index of PU film exposed to various environments

\begin{tabular}{|c|c|c|c|c|c|c|}
\hline \multirow{2}{*}{ Environment } & \multicolumn{7}{|c|}{ Time, $\mathrm{h}$} \\
\cline { 2 - 7 } & 0 & 20 & 60 & 120 & 160 & 200 \\
\hline $\mathrm{UV}$ & 0 & 4.25 & 3.85 & 5.35 & 6.00 & 6.00 \\
\hline $\mathrm{O}_{3}$ & 0 & 0.45 & 1.10 & 2.20 & 2.50 & 3.05 \\
\hline $\mathrm{O}_{3} / \mathrm{UV}$ & 0 & 33.50 & 37.80 & 39.30 & 38.75 & 39.80 \\
\hline $\mathrm{O}_{3}+\mathrm{UV}$ & 0 & 4.70 & 4.95 & 7.55 & 8.50 & 9.05 \\
\hline
\end{tabular}

The colour difference of the films exposed to UV radiation is significantly greater than that to $\mathrm{O}_{3}$ atmosphere at the same time, and the yellowness index of the film

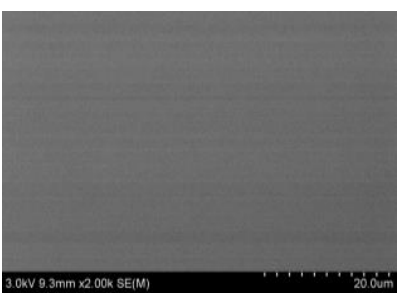

a

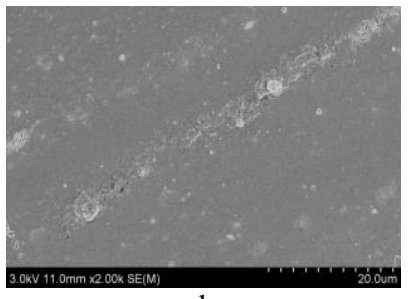

b exposed to UV radiation is significantly greater than that to $\mathrm{O}_{3}$ atmosphere at the same time. This means that the degradation of the film induced by UV radiation is significantly greater than that induced by $\mathrm{O}_{3}$ atmosphere. The probable reasons are as follows, ozone-induced oxidation reaction is a selectivity process with the low rate, and dipolar structure in ozone can react with the unsaturated bond, causing the breakage of the bond. Energy provided by UV radiation is enough to break the chemical bonds in polyurethane, and the internal structure of the polyurethane is not easy to be oxidized directly without the activation of ultraviolet [14]. Therefore, the polyurethane is more sensitive to UV radiation.

\subsection{SEM micrograph}

Fig. 3 presents SEM micrographs of PU films before and after $200 \mathrm{~h}$ exposure of $\mathrm{UV}$ radiation, $\mathrm{O}_{3}$ atmosphere, and $\mathrm{UV} / \mathrm{O}_{3}$ integrated environment. Fig. 3 a shows that the surface of the unexposed PU film is relatively smooth and uniform. Fig. $3 \mathrm{~b}$ shows that some noticeable degradation products with different size are formed on the film surface after $200 \mathrm{~h}$ of $\mathrm{O}_{3}$ exposure. The probable reasons are as follows, a part of the polymer chain in the film is broken and benzene ring is opened after the erosion of atomic oxygen generated from ozone. This leads to the macromolecular particles escaping. The uppermost layer of the film without any cracks is still relatively ductile and coherent, indicating that ozone only causes the degradation of the film surface layer [15]. Fig. $3 \mathrm{c}$ shows that some blisters with different size and depth are formed on the film surface, and some blisters have broken after $200 \mathrm{~h}$ of UV exposure. It can be speculated that blisters are formed on the film surface during the initial phase of film degradation. These blisters increase in size continuously and finally break with increasing exposure time. These blisters may be attributed to the degradation of the film exposed to UV radiation, which resulted from the scission of the molecular chain in the film and the release of the gas [16-18]. Fig. $3 \mathrm{~d}$ shows that not only the surface, but also the bulk of the film is degraded. A large number of strip blisters cover the film surface, in which some blisters are formed, and some blisters have shrunk. The micro-cracks in all directions are formed throughout the film surface. The probable reasons are as follows, in the presence of ultraviolet radiation, the ozone is excited to generate more active oxygen atom, which causes the degradation of film surface and the increase of the degradation products of the films. Meanwhile, the ozone can easily act on the interior of the film due to the generation of cracks and accelerate the degradation of the polyurethane film [19].

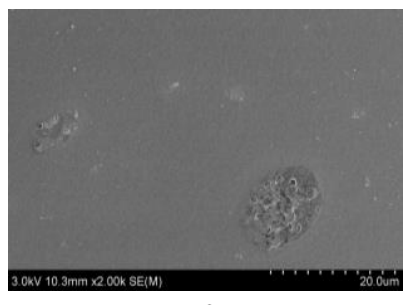

c

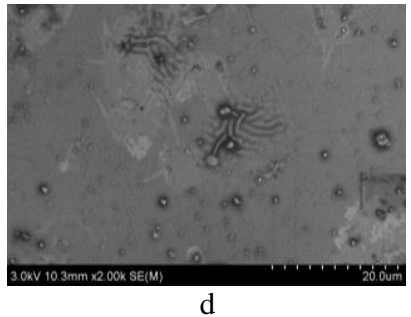

d

Fig. 3. a-SEM images of PU film surface before exposure; b-after $200 \mathrm{~h}$ exposure in $\mathrm{O}_{3}$ atmosphere; $\mathrm{c}-$ after $200 \mathrm{~h}$ exposure in $\mathrm{UV} / \mathrm{O}_{3}$ integrated environment; $\mathrm{d}-$ after $200 \mathrm{~h}$ of $\mathrm{UV}$ radiation 
This suggests that the films are vulnerable to degradation in following environment order: $\mathrm{O}_{3}<\mathrm{UV}<\mathrm{UV} / \mathrm{O}_{3}$, and an obvious synergism between $\mathrm{UV}$ and $\mathrm{O}_{3}$ exists in accelerating the degradation of the polyurethane film.

\section{CONCLUSIONS}

1. UV absorbance, the colour difference, and the yellowness index of the polyurethane films gradually increase with increasing exposure time during exposure to $\mathrm{UV}$ radiation, $\mathrm{O}_{3}$ atmosphere, and $\mathrm{UV} / \mathrm{O}_{3}$ integrated environment, respectively. The absorption of the main functional groups of $-\mathrm{NH} /-\mathrm{OH}$ and $-\mathrm{C}=\mathrm{O}$ bands in FT-IR spectra gradually increase with increasing exposure time. Some degradation products and blisters are formed on the film surface after exposure to $\mathrm{O}_{3}$ atmosphere and $\mathrm{UV}$ radiation, respectively. There are strip blisters and micro-cracks on the film surface after $\mathrm{UV} / \mathrm{O}_{3}$ exposure.

2. The films exposed to various environments have different the colour difference, the yellowness index, UV-Vis spectra, and FT-IR spectra. The films are vulnerable to degradation and yellowing in following environment order: $\mathrm{O}_{3}<\mathrm{UV}<\mathrm{UV} / \mathrm{O}_{3}$.

3. An obvious synergism between $\mathrm{UV}$ and $\mathrm{O}_{3}$ in accelerating the ageing of the polyurethane films exists.

\section{Acknowledgement}

The authors acknowledge Aerospace Science and Technology Innovation Fund for providing financial support for this study (Grant No. 2014-YF-0416).

\section{REFERENCES}

1. Nichetti, D., Grizzuti, N. Determination of The Phase Transition Behavior of Thermoplastic Polyurethanes from Coupled Rheology/DSC Measurements Polymer Engineering \& Science 44 (8) 2004: pp.1514-1521. http://dx.doi.org/10.1002/pen.20148

2. Jozef, R., Agnes, L.D., Lavédrine, B., Bertrand, L., Lyda, M.R., Marta, M., Katarína, C., Ivica, J. Assessing the Progress of Degradation in Polyurethanes by Chemiluminescence and Thermal Analysis II. Flexible Polyether- and Polyester-Type Polyurethane Foams Polymer degradation and stability 96 (4) 2011: pp. $462-469$. http://dx.doi.org/10.1016/j.polymdegradstab.2011.01.012

3. Shi, A., Koka, S., Ullett, J. Performance Evaluation on the Weathering Resistance of Two USAF Coating Systems (Standard 85285 Topcoat Versus Fluorinated APC Topcoat) Via Electrochemical Impedance Spectroscopy Progress in organic coatings 52 (3) 2005: pp.196-209. http://dx.doi.org/10.1016/j.porgcoat.2004.11.005

4. Šimon, P., Fratričová, M., Schwarzer, P., Wilde, H.W. Evaluation of the Residual Stability of Polyurethane Automotive Coatings by DSC Journal of Thermal Analysis and Calorimetry 84 (3) 2006: pp. 679-692. http://dx.doi.org/10.1007/s10973-005-7549-z

5. Singh, R.P., Tomer, N.S., Bhadraiah, S.V. Photo-oxidation Studies on Polyurethane Coating: Effect of Additives on Yellowing of Polyurethane Polymer degradation and stability 73 (3) 2001: pp. $443-446$.
6. Egerton, T.A., $\quad$ Everall, N.J., $\quad$ Mattinson, J.A., Kessell, L.M., Tooley, I.R. Interaction of $\mathrm{TiO}_{2}$ NanoParticles with Organic UV Absorbers Journal of Photochemistry and Photobiology A: Chemistry 193 (1) 2008: pp. $10-17$. http://dx.doi.org/10.1016/j.jphotochem.2007.06.001

7. Mahltig, B., Böttcher, H., Rauch, K., Dieckmann, U., Nitschec, R., Fritz, T. Optimized UV Protecting Coatings by Combination of Organic and Inorganic UV Absorbers Thin Solid Films $485(1-2)$ 2005: pp. 108-114.

8. Croll, S.G., Skaja, A.D. Quantitative Spectroscopy to Determine the Effects of Photodegradation on a Model Polyester-Urethane Coating Journal of Coatings Technology 75 (945) 2003: pp. 85-94. http://dx.doi.org/10.1007/BF02720155

9. Diepens, M., Gijsman, P. Photodegradation of Bisphenol a Polycarbonate Polymer Degradation and Stability 92 (3) 2007: pp. $397-406$. http://dx.doi.org/10.1016/j.polymdegradstab.2006.12.003

10. Bedoya, F.E., Gallego, L.M., Bermúdez, A., Castaño, J.G., Echeverría, F., Calderón, J.A., Maya, J.G. New Strategy to Assess the Performance of Organic Coatings During Ultraviolet-Condensation Weathering Tests Electrochimica Acta 124 2014: pp. 119-127. http://dx.doi.org/10.1016/j.electacta.2013.09.064

11. Wang, Y.Z., Wang, H.Y., Li, X.S., Liu, D., Jiang, Y.F., Sun, Z.H. $\mathrm{O}_{3} / \mathrm{UV}$ Synergistic Ageing of Polyester Polyurethane Film Modified by Composite UV Absorber Journal of Nanomaterials 2013 2013: pp. 1-7.

12. Nichols, M.E., Gerlock, J.L. Rates of Photooxidation Induced Crosslinking and Chain Scission in Thermoset Polymer Coatings II. Effect of Hindered Amine Light Stabilizer and Ultraviolet Light Absorber Additives Polymer Degradation and Stability 69 (2) 2000: pp. 197-207.

13. Liu, L.B. Water Resistance of Polyurethane Elastomer Journal of elastomers and plastics 5 1995: pp. 13-17.

14. Rosu, D., Rosu, L., Cascaval, C.N. IR-Change and Yellowing of Polyurethane as a Result of UV Irradiation Polymer Degradation and Stability 94(4) 2009: pp. 591-596. http://dx.doi.org/10.1016/j.polymdegradstab.2009.01.013

15. Rasoul, F.A., Hill, D.J.T., Forsythe, J.S., O'Donnell, J.H., George, G.A., Pomery, P.J., Young, P.R., Connell, J.W. Surface Properties of Fluorinated Pis Exposed to VUV and AO Journal of Applied Polymer Science 58 1995: pp. $1857-1864$. http://dx.doi.org/10.1002/app.1995.070581024

16. Yang, X.F., Tallman, D.E., Bierwagen, G.P., Croll, S.G., Rohlik, S. Blistering and Degradation of Polyurethane Coatings Under Different Accelerated Weathering Tests Polymer degradation and stability 77 (1) 2002: pp. $103-109$

17. Yang, X.F., Vang, C., Tallman, D.E., Bierwagen, G.P., Croll, S.G., Rohlik, S. Weathering Degradation of a Polyurethane Coating Polymer Degradation and Stability 74 (2) 2001: pp. $341-351$. http://dx.doi.org/10.1016/S0141-3910(01)00166-5

18. Furukawa, M., Wakiyama, K. Deterioration of Novel Polyester Urethane Elastomers in Outdoor Exposure Polymer Degradation and Stability $65(1)$ 1999: pp. $15-24$. http://dx.doi.org/10.1016/S0141-3910(98)00209-2

19. Rashvand, M., Ranjbar, Z., Rastegar, S. Nano Zinc Oxide as a UV-Stabilizer for Aromatic Polyurethane Coatings Progress in Organic Coatings 71 (4) 2011: pp. 362-368. 